\begin{tabular}{ll}
\hline Thabiea : Journal of Natural Science Teaching \\
Program Studi Tadris Ilmu Pengetahuan Alam \\
Institut Agama Islam Negeri Kudus \\
http://journal.stainkudus.ac.id/index.php/Thabiea \\
$p$-issn: 25808474
\end{tabular}

\title{
Analisis Literasi Pendidikan STEM pada Siswa dan Pemahaman Konsep IPA Melalui Peta Konsep di SDN Palasari II
}

\author{
Oktian Fajar Nugroho ${ }^{\text {a, } 1}$, Muhammad Aqmal Nurcahyo b \\ ${ }^{a}$ Universitas Esa Unggul, Jakarta, Indonesia \\ bUniversitas Nahdlatul Ulama Kalimantan Barat, Pontianak, Indonesia \\ ${ }^{1}$ oktian.fajar@esaunggul.ac.id
}

\begin{tabular}{ll}
\hline Kata kunci: & ABSTRAK \\
\hline Peta Konsep & Di banyak negara di seluruh dunia, ada peningkatan penekanan pada peningkatan \\
STEM & pembelajaran sains melalui pendidikan STEM. Literasi pendidikan STEM harus lebih \\
Literasi & banyak dianalisa di Indonesia. Sebagai contoh, mengembangkan beberapa metode atau \\
& pendekatan tentang pendidikan STEM masih dikembangkan oleh banyak peneliti dapat \\
& meningkatkan pengetahuan tentang pendidikan STEM. Namun, pra-penelitian tentang \\
& literasi siswa tentang pendidikan STEM harus dilakukan untuk mengetahui \\
& karakteristik murid Indonesia. Tujuan penelitian ini adalah untuk mengetahui literasi \\
& STEM pada siswa sekolah dasar. Tulisan ini menyajikan fakta tentang pendidikan \\
& STEM di salah satu Sekolah Dasar di Tangerang. Penelitian ini dilakukan dengan \\
& randomized control group pretest and posttest. Hasil penelitian ini memberikan \\
& beberapa bukti indikator pendidikan STEM yang dapat membantu peneliti lain untuk \\
& mengembangkan pendidikan STEM di Indonesia. Ada kebutuhan untuk penelitian \\
& tentang pendidikan STEM untuk memberikan para siswa dengan keterampilan abad \\
& 21. Namun, kami menyarankan untuk mengembangkan STEM Education yang \\
& berfokus pada siswa Indonesia dan kondisi fasilitas sekolah.
\end{tabular}

\begin{tabular}{ll}
\hline Keyword: & ABSTRACT \\
\hline Concept Map & Analysis of Students' STEM Design Literacy and Conceptual Understanding of \\
STEM & Science through Concept Map in SDN Palasari II. In Many Countries Around The \\
Literacy & World, There Has Been An Increasing Emphasis On Improving science learning \\
& through STEM education. The literacy of STEM education should more analyze in \\
& Indonesia. For the example, developing some methods or approaches about STEM \\
& education still developed by many researchers it may increasing of knowledge about \\
& STEM education. However, pre research about students' literacy about STEM \\
& education should be conducted to know the Indonesian pupil's characteristics. He aims \\
& of this study are to gain the imformation of students' STEM literacy. This paper \\
& presents the fact about STEM education in one Elementary School in Tangerang. This \\
& study was conducted by randomized control group pretest and posttest. The results of \\
& this study provided some evidence of STEM education indicators that may help other \\
& researcher to develop STEM education in Indonesia. There is need for research about \\
& STEM education to provide students with $21^{\text {st }}$ century skill. However, we suggest to \\
& develop STEM Education focusing on Indonesian pupils and the condition of school's \\
facilities.
\end{tabular}

Copyright $\odot 2018$ Institut Agama Islam Negeri Kudus. All Right Reserved

\section{Pendahuluan}

STEM Education telah diidentifikasi oleh banyak peneliti di seluruh dunia. Akronim dari STEM yaitu Science, Technology, Engineering,dan Mathematics. Pendidikan STEM telah diteliti oleh banyak peneliti diberbagai Negara untuk mempersiapkan kemampuan siswa agar mempunyai keterampilan yang dapat digunakan di abad 21 (Pimthong \& Williams, 2018). Ide besar dalam mengembangkan pendidikan STEM bermula dari hasil Trends in Internasional Mathematics and Science Study (TIMMS) tahun 2011. Hasil tersebut membandingkan 
hasil TIMMS negara Amerika dibandingkan dengan negara yang lain (Mullis et al, 2012). Dari hasil tersebut, beberapa peneliti di Amerika memiliki penekanan besar pada peningkatan minat dan pemahaman siswa tentang STEM.

Dalam studi ini, peneliti menggunakan peta konsep sebagai intervensi dalam upaya mengetahui pengaruh peta konsep dalam peningkatan Literasi STEM. Menurut Wendel dan Rogers (2013) pengembangan strategi pembelajaran yang menggambungkan desain teknik untuk pembelajaran sains perlu ditingkatkan. Oleh sebab itu, intervensi dalam penelitian menggunakan peta konsep tetap merujuk kepada desain teknik. Dengan merujuk kepada desain teknik dianggap sebagai model pembelajaran yang menjanjikan untuk meningkatkan pembelajaran sains dan pencapaian pembelajarannya (Yanyan, Zhinan, Menglu, \& Ting Wen , 2016). Engineering thinking meliputi: sistem berpikir, beradaptasi, penemuan masalah, pemecahan masalah kreatif, visualisasi dan peningkatan (Lucas in King \& English, 2016).

Telah terjadi peningkatkan keterampilan melalui skenario Industry 4.0 dan keterampilan yang dibutuhkan di abad 21. Kerangka keterampilan abad 21 adalah komunikasi dan kolaborasi, berpikir kritis dan pemecahan masalah, dan kreativitas dan inovasi. Melalui kerangka keterampilan abad 21 itu menunjukkan fakta literasi STEM siswa. Berdasarkan hasil PISA 2017, menurut Schleicher, (2018) hasil PISA untuk siswa Indonesia menunjukkan hasil yang rendah, bahwa hanya ada satu siswa yang berhasil berada diperingkat teratas dan sisanya sebanyak 74 siswa berada di peringkat bawah.

Pemerintah Indonesia telah mengidentifikasi keaksaraan sains, teknologi, teknik dan matematika melalui hasil PISA di tahun ke tahun. Hasil PISA diidentifikasi rendah dibandingkan dengan negara lain di dunia.

Indonesia telah mengumpulkan informasi dalam studi penelitian yang dilakukan para akademisi untuk menemukan solusi yang tepat untuk meningkatkan keterampilan siswa dan pemahaman tentang pendidikan STEM. Pendidikan STEM yang diterapkan akan berdampak kepada pola pikir siswa dalam menentukan pandangan mereka tentang STEM dan karir dimasa depan (zecharia et al. 2014).

Berdasarkan permasalah yang timbul yaitu bagaimana meningkatkan literasi STEM pada siswa dan solusi yang tepat untuk meningkatkan keterampilan abad 21. Beberapa literatur yang merujuk dalam meningkatkan keterampilan abad 21 dan literasi akan dijelaskan dalam tinjauan literatur. Menurut (Bagiati et al 2016; Barret 2014) Siswa bekerja dalam pasangan atau tim untuk membangun pengetahuan latar belakang dan keterampilan yang diperlukan untuk tantangan desain melalui tangan pada kegiatan atau penyelidikan yang dipandu. Menggambar solusi yang mungkin dan penggunaan pencatatan dapat membantu siswa untuk mengidentifikasi faktor kunci untuk memecahkan masalah dan untuk menganalisis perkembangan ide (Guzey,). Mengenai mereka, peneliti telah merancang kegiatan kelas dengan kolaborasi dan menggambar solusi yang mungkin untuk memecahkan masalah yang diberikan oleh guru.

Dalam rangka meningkatkan kemampuan siswa dalam keterampilan abad ke21, berdasarkan pada studi ini, hal ini dimungkinkan karena siswa secara aktif membangun pengetahuan mereka secara efektif ketika mereka secara aktif membangun produk dalam konteks dunia nyata (Schnittka et al, 2016; Yanyan et al., 2016) . Selain itu, di kelas yang melakukan kegiatan kolaborasi bertujuan untuk meningkatkan keterampilan komunikasi mereka sebagai salah satu keterampilan abad ke21. (Yanyan et al., 2016).

Ada beberapa kesamaan dari pelaksanaannya yang merupakan proses desain teknik yang ditunjukkan di bawah ini (Yanyan dkk, 2016):

a. Perkenalan

b. Identifikasi masalah

c. Kembangkan solusi yang memungkinkan

d. Tentukan solusi terbaik

e. Buat prototipe

f. Uji prototipe

g. Mendesain ulang prototipe

Menurut Lalor, SB (2014) Peta Konsep merupakan intervensi yang ditujukan untuk meningkatkan pemahaman konsep dan hubungan antar konsep serta dapat menjadi bahan evalusi guru untuk menganalisis pemahaman konsep siswa. Dalam pembuatan peta konsep, salah satu domain dari keterampilan abad 21 yaitu kreatifitas dapat dilihat dalam pembuatan peta konsep. Selain itu, keterampilan komunikasi dapat dilihat saat siswa menjelaskan hasil peta konsep, hal tersebut juga dapat dilihat dengan memberikan kesempatan siswa untuk 
mempresentasikan hasil peta konsep mereka. Irisan antara Peta Konsep dan keterampilan abad 21 dapat dianalisis dan memungkinkan untuk diterapkan untuk dijadikan intervensi dalam pembelajaran dikelas.

Contohnya, dalam mengajar fisiologi, siswa didorong untuk membangun peta konsep yang secara aktif mengintegrasikan subjek-subjek komponen dan mengidentifikasi hubungan kausal untuk mencerminkan hasil pembelajaran yang diinginkan (Lian, MWS, 2009). Sementara peta konsep sering menjadi tendensi untuk memetakan hasil dari siswa dalam memberikan cara yang akurat dan sederhana untuk mencatat kemajuan siswa, harus ditekankan bahwa pendekatan ini memiliki potensi kehilangan informasi penting (Lalor, SB 2014).

\section{Metode}

Desain yang digunakan dalam penelitian ini adalah kuantitatif dan kualitatif (mix method). Sasaran penelitian yaitu siswa kelas 5 di SDN Palasari II. Dalam penelitian ini ada tes untuk mengetahui pemahaman konsep siswa melalui pre dan post test. Jenis metode dalam penelitian ini adalah Randomized Control Group PretestPosttest Design Metode ini ditunjukkan di bawah ini:

Tabel 1. Metodologi

\begin{tabular}{|l|c|c|c|}
\hline \multicolumn{1}{|c|}{ Group } & Pretest & Implementasi & Posttest \\
\hline $\begin{array}{l}\text { Control } \\
\text { Group }\end{array}$ & $\mathrm{T} 1$ & $\mathrm{Y}$ & $\mathrm{T} 2$ \\
\hline $\begin{array}{l}\text { Eksperimen } \\
\text { Group }\end{array}$ & $\mathrm{T} 1$ & $\mathrm{Y}+\mathrm{X}$ & $\mathrm{T} 2$ \\
\hline
\end{tabular}

Berdasarkan tabel 1 diatas, terdapat dua kelas sebagai sample penelitian. Kelas pertama yaitu kelas kontrol dengan implementasi model cooperative learning berbasis STEM dengan merujuk kepada permasalahan yang sudah dibuat oleh guru (Y) sedangkan kelas eksperimen implementasi model cooperative learning berbasis STEM dengan tambahan pembuatan peta konsep oleh siswa $(\mathrm{Y}+\mathrm{X})$.

Sampel dari penelitian ini adalah dua kelas 5 sekolah dasar dari populasi. Random cluster sampling digunakan sebagai teknik sampling. Hypothesis : $\mathrm{H}_{\mathrm{o}}$ pada penelitian ini adalah "tidak terdapat perbedaan yang signifikan literasi STEM pada siswa dan pemahaman konsep IPA melalui peta konsep di SDN Palasari II" sedangkan $\mathrm{H}_{1}$ "Terdapat perbedaan signifikan literasi STEM pada siswa dan pemahaman konsep IPA melalui peta konsep di SDN Palasari II"

\section{Hasil dan pembahasan}

Berdasarkan penelitian yang telah dilakukan, hasil pada penelitian ini terkait tentang analisis literasi STEM yang diharapkan dapat lebih berkembang. Data kuesioner tidak berpengaruh signifikan untuk melihat indikator dalam desain STEM. Penguasaan siswa terhadap data hasil konsep pemahaman diperoleh melalui tes tertulis dengan pertanyaan pilihan ganda dan pembuatan peta konsep. Peningkatan peta konsep siswa diperoleh dengan pretest dan posttest sedangkan fakta tentang literasi STEM siswa diperoleh dengan kuesioner dan lembar observasi. Hasilnya dirangkum dalam tabel 2 di bawah ini:

\begin{tabular}{|c|c|c|c|c|}
\hline \multirow{2}{*}{ Ket } & \multicolumn{2}{|c|}{ Expt Group } & \multicolumn{2}{c|}{ Controlgroup } \\
\cline { 2 - 5 } & Pretest & Posttest & Pretest & Posttest \\
\hline $\mathrm{N}$ & 39 & 39 & 36 & 39 \\
\hline Mean & 67 & 84,63 & 48,36 & 64,36 \\
\hline Tinggi & 90 & 100 & 70 & 80 \\
\hline Rendah & 40 & 75 & 35 & 45 \\
\hline Gain & \multicolumn{2}{|c|}{18,88} & \multicolumn{2}{c|}{11,79} \\
\hline N-Gain & 0,53 (Medium) & 0,21 (Low) \\
\hline Normal & \multicolumn{3}{|c|}{ Sig. $\geq 0,05=$ Normal } \\
\hline Sig. & \multicolumn{2}{|c|}{0,153} & 0,079 \\
\hline $\begin{array}{c}\text { Kesimp } \\
\text { ulan }\end{array}$ & \multicolumn{3}{|c|}{ Normal } \\
\hline $\begin{array}{c}\text { Homoge } \\
\text { niti test }\end{array}$ & \multicolumn{3}{|c|}{ Sig. $\geq 0,05=$ Homogen } \\
\hline Sig. & \multicolumn{3}{|c|}{0,102} \\
\hline $\begin{array}{c}\text { Kesimp } \\
\text { ulan }\end{array}$ & \multicolumn{3}{|c|}{ Homogen } \\
\hline $\begin{array}{c}\text { Indepen } \\
\text { dent- } \\
\text { Sample } \\
\text { T-test }\end{array}$ & \multicolumn{3}{|c|}{ Sig. (2-tailed) $\geq 0,05=\mathrm{H}_{0}$ Accepted } \\
\hline Sig. & \multicolumn{3}{|c|}{0,00} \\
\hline $\begin{array}{c}\text { Kesimpul } \\
\text { an }\end{array}$ & Ho Ditolak, $\mathrm{H}_{1}$ Diterima \\
\hline Berdasarkan hasil yang ditunjukkan di
\end{tabular}

atas, rata-rata pemahaman konsep siswa sedikit meningkat signifikan dilihat dari gain kelas kontrol sebesar 11,79 dan kelas eksperimen sebesar 18,88. Konsep implementasi peta sebagai intervensi telah berhasil dilakukan. Hasilnya menunjukkan peningkatan pemahaman konsep siswa. Peta konsep dapat digunakan untuk meningkatkan pemahaman konsep siswa. 
Implementasi peta konsep sebagai perlakuan untuk menunjukkan literasi STEM tidak benarbenar akurat, penelitan selanjutnya harus menemukan metode atau pendekatan lain untuk melihat literasi STEM siswa.

Hasil penelitian ini selaras dengan hasil penelitian sebelumnya, beberapa penelitian menunjukkan persepsi siswa dan kurangnya pemahaman subjek STEM dan karir sering menyebabkan banyak orang muda terputus dari STEM, merasa bahwa itu bukan untuk mereka.

Sementara fakta tentang literasi STEM dan implementasi peta konsep dalam pembelajaran kooperatif berbasis STEM untuk menganalisis literasi STEM siswa dan pemahaman konseptual sains melalui peta konsep sudah dilakukan. Studi ini menunjukkan kepada kita dampak dari peta konsep untuk meningkatkan pemahaman konsep siswa ditingkatkan tetapi kita harus menemukan metode lain untuk lebih menganalisis literasi STEM. Dengan demikian, peta konsep membantu guru untuk menganalisis pemahaman konsep mereka. Pembelajaran kooperatif adalah cara terbaik dalam penelitian ini namun masih kurang akurat dalam menganalisis literasi STEM.

\section{Ucapan Terimakasih}

Penulis ingin mengucapkan terima kasih kepada Universitas Esa Unggul, Jakarta, Indonesia dan Universitas Nahdlatul Ulama Kalimantan Barat, Pontianak, Indonesia yang telah mendukung dalam penelitian ini.

\section{Referensi}

Bagiati, A., \& Evangelou, D. (2016). Practicing engineering while building with blocks: identifying engineering thinking. European Early Childhood Education Research Journal, 24(1), 67-85. doi:10.1080/1350293X.2015.1120521

Barrett, B. S., Moran, A. L., \& Woods, J. E. (2014). Meteorology meets engineering: an interdisciplinary STEM module for middle and early secondary school students. International Journal of STEM
Education, 1(1), 6. doi:10.1186/21967822-1-6

Lalor, S.B. (2014) The Effects of Using Concept Mapping for Improving Advanced Level Biology Students' Lower and High Order Cognitive Skill, International Journal of Science Education, 36 (5), 839-864, doi: 10.1080/095006 93.2013.829255

Lian, M. W. S., (2009) An Investigation into High Achieverand Low Achiever Knowledge Organisation and Knowledge Processing in Concept Mapping: A Case Study, Reserach in Science Education, 39(3), 337-352 DOI: org/10.1080/03055698.2009.643100

Guzey, S. S., Moore, T. J., Harwell, M., \& Moreno, M. (2016). STEM Integration in Middle School Life Science: Student Learning and Attitudes. Journal of Science Education and Technology, 25(4), 550560. doi:10.1007/s10956- 016-9612-x

Mullis, I. V. S., Martin, M. O., Foy, P., \& Drucker, K. T. (2012). PIRLS 2011 international results in reading. Chestnut Hill. MA: TIMSS \& PIRLS International Study Center, Boston College.

Pimthong, P., \& William, J. (2018). Preservice teachers' understanding of STEM education. Kasetsart Journal of Social Science, 39(1), 1-7.

Schleicher, A (2018), World Class: How to build a 21st-century school system, Strong Performers and Successful Reformers in Education, OECD Publishing, Paris.

Schnittka, C. G., Evans, M. A., Won, S. G. L., \& Drape, T. A. (2016). After-School Spaces: Looking for Learning in All the Right Places. Research in Science Education, 46(3), 389-412. doi:10.1007/s11165-0159463-0

Yanyan, L., Zhinan, H., Menglu, J., \& TingWen, C. (2016). The Effect on Pupil's Science Performance and ProblemSolving Ability through Lego: An Engineering Design-based Modeling Approach. Journal of Educational Technology \& Society, 19(3), 143-156. 